\title{
Multivariate multilevel analyses of examination results
}

\author{
Min Yang, Harvey Goldstein, William Browne and Geoffrey Woodhouse \\ Institute of Education, London, UK
}

[Received November 2000. Revised May 2001]

\begin{abstract}
Summary. In the study of examination results much interest centres on comparisons of curriculum subjects entered and the correlation between these at individual and institution level based on data where not every individual takes all subjects. Such 'missing' data are not missing at random because individuals deliberately select subjects that they wish to study according to criteria that will be associated with their performance. In this paper we propose multivariate multilevel models for the analysis of such data, adjusting for such subject selection effects as well as for prior achievement. This then enables more appropriate institutional comparisons and correlation estimates. We analyse A- and AS-level results in different mathematics papers of 52587 students from 2592 institutions in England in 1997. Although this paper is concerned largely with methodology, substantive findings emerge on the effects of gender, age, intakes of General Certificate of Education pupils, examination board and establishment type for A- and AS-level mathematics.
\end{abstract}

Keywords: Examination choice; Institutional differences; Mathematics examinations; Missing data; Multilevel model; Multivariate response model

\section{Introduction}

Yang and Woodhouse (2001) describe the analysis of a large data set on pupils in English schools and colleges catering for pupils 16-19 years old. The data set contains results of General Certificate of Education (GCE) advanced level (A-level) and advanced supplementary level (AS-level) examinations of all 696660 individual candidates in 2794 institutions over a 4-year period. The AS-level examination is normally, but not always, taken after 1 year of study following sitting the General Certificate of Secondary Education (GCSE) and involves approximately half the amount of time as the A-level examination taken after 2 years. Yang and Woodhouse (2001) looked at comparisons between institutions after adjustments for performances in the GCSE examinations taken by the same candidates 2 years earlier. Among other findings, they showed that the adjustments reduced apparent differences between various types of institution and between males and females. Their analyses, however, were conducted using the total A- and AS-level 'points score' for each pupil, i.e. the sum of points for all the examinations taken: each examination grade is assigned a score ranging from 1 to 10 .

Much interest centres on comparisons of curriculum subjects entered and the correlation between these at individual and institution level. Thus, for example, institutions which produce high scores for one science subject may be expected to do so for others, although individual institutions which do not follow such a pattern may also be of interest. In principle

\footnotetext{
Address for correspondence: Min Yang, Department of Mathematical Sciences, Institute of Education, 20 Bedford Way, London, WC1H 0AL, UK.

E-mail: m.yang@ioe.ac.uk
} 
we could fit multivariate multilevel models to such data, regarding this as a case where potentially all individuals have responses for all curriculum subjects but where for any one individual most responses are missing (Goldstein, 1995). The multivariate responses are treated as defining the lowest level of a hierarchy, being 'nested' within individuals. One of the difficulties with fitting such a multivariate model to the A- and AS-level data is that the 'missingness' is non-random: individuals deliberately select subjects that they wish to study according to criteria which will be associated with their performance. This is a general problem with many kinds of data where a choice of response variable operates. Fitting other covariates such as GCSE scores may move the assumption closer towards the assumption of missing at random, but it may not always be effective.

In this paper we explore a practical method for handling such data and try to specify models around certain substantive questions of research interest. We have chosen to study only A- and AS-level mathematics since this has several options that pupils can choose between. Thus, our approach allows us to separate students' performances in mathematics into the constituent components, taking account of the choice of combination. It extends the usual 'value-added' analysis of examination results by allowing us to compare institutions in terms of each examination outcome. Although we do not pursue it in the present paper our approach would also allow a study of the effects of school examination entry policies on results.

In the next section we introduce the data and this is followed by various models. The data which are analysed can be obtained from

http://www.blackwellpublishers.co.uk/rss/

\section{Data}

A full description of the data set is given by Yang and Woodhouse (2001). Briefly, data for each pupil were matched from A- and AS-level examinations back to GCSE, incorporating the individual GCSE total point score, the point score for GCSE mathematics and the point score for GCSE English. 4 years' data are available for pupil examination entries in 1993, 1994, 1995 and 1997 and in this analysis we use only the data for 1997. This gives 61116 entries for 53798 students from 2607 institutions from six examination boards. Information on students' ages in months, gender and type of educational establishment are also available.

According to the course code in the database, supplied by the UK Department for Education and Employment, data entries covered 10 different types of mathematics as in Table 1. Among the students, $46727(86.9 \%)$ had a single entry, $6829(12.7 \%)$ had double entries and $237(0.44 \%)$ had three or four entries. The mean point score in Table 1 is the average point score on all entries for each particular entry type by A- and AS-level.

The definition of the subject is not consistent across the six examination boards. In particular the courses labelled DD, PA, PS, PM and ADD were present for only a single board. All entries for DD were for an AS-level course with 65 single DD and 44 entries in DD plus the AS-level main mathematics. Additional mathematics had only 67 entries from one examination board. Statistics is another subject with $68 \%$ of entries at AS-level. For simplicity, and because the main thrust of this paper is methodological, we have excluded entries on DD, additional mathematics and statistics from the analysis.

For entries on subjects PA, PS and PM, single entries were $84 \%, 95 \%$ and $78 \%$ respectively, and the most common double entries were those paired with $\mathrm{F}$, which were $15 \%$, 
Table 1. Mathematics entries and the mean A- and AS-level point scores $\dagger$

\begin{tabular}{|c|c|c|c|c|c|}
\hline $\begin{array}{l}\text { Mathematics } \\
\text { entry }\end{array}$ & $\begin{array}{l}\text { Number of } \\
\text { entries }(\%) \\
\text { A-level }\end{array}$ & $\begin{array}{c}\text { Mean point score } \\
\text { (standard deviation), } \\
\text { A-level }\end{array}$ & $\begin{array}{c}\text { Number of } \\
\text { entries (\%), } \\
\text { AS-level }\end{array}$ & $\begin{array}{c}\text { Mean point score } \\
\text { (standard deviation), } \\
\text { AS-level }\end{array}$ & $\begin{array}{c}\text { Examination } \\
\text { board }\end{array}$ \\
\hline Main (M) & $44672(84.24)$ & $6.00(3.36)$ & $3825(47.32)$ & $1.26(1.51)$ & All six \\
\hline Pure $(\mathrm{P})$ & $640(1.21)$ & $7.60(3.19)$ & $667(8.25)$ & $1.27(1.46)$ & All except JMB \\
\hline $\begin{array}{l}\text { Decision and } \\
\text { discrete (DD) }\end{array}$ & $0(0.00)$ & & $153(1.89)$ & $1.62(1.55)$ & AEB \\
\hline Applied (A) & $399(0.75)$ & $7.26(3.22)$ & $585(7.24)$ & $1.73(1.64)$ & $\begin{array}{l}\text { AEB, LOND, } \\
\text { OXCAM }\end{array}$ \\
\hline $\begin{array}{l}\text { Pure and } \\
\text { applied (PA) }\end{array}$ & $1329(2.51)$ & $5.90(3.48)$ & $149(1.84)$ & $1.03(1.03)$ & JMB \\
\hline $\begin{array}{l}\text { Pure and } \\
\text { statistics (PS) }\end{array}$ & $526(0.99)$ & $4.55(3.41)$ & 0 & & JMB \\
\hline $\begin{array}{l}\text { Pure and } \\
\text { mechanics } \\
(\mathrm{PM})\end{array}$ & $529(1.00)$ & $6.45(3.48)$ & 0 & & JMB \\
\hline Further (F) & $4404(8.30)$ & $7.55(2.98)$ & 1608 (19.89) & $2.97(1.76)$ & All six \\
\hline $\begin{array}{l}\text { Additional } \\
\text { (ADD) }\end{array}$ & $28(0.05)$ & $7.14(4.05)$ & $39(0.48)$ & $3.31(1.88)$ & OXCAM \\
\hline Statistics (S) & $505(0.95)$ & $5.30(3.40)$ & 1058 (13.09) & $1.54(1.58)$ & All six \\
\hline Total & $53032(100.0)$ & $6.14(3.34)$ & $8084(100.0)$ & $1.68(1.58)$ & \\
\hline
\end{tabular}

$\dagger$ The points allocated for A-level (and for AS-level in parentheses) are as follows: A-grade, 10 (5); B-grade, 8 (4); Cgrade, 6 (3); D-grade, 4 (2); E-grade, 2 (1); F-grade, 0 (0). The examination boards in 1997 are coded as follows: AEB, Associated Examining Board; CAMB, Cambridge; LOND, London; OXF, Oxford; JMB, Joint Matriculation Board; OXCAM, Oxford and Cambridge.

†The Cambridge and Oxford boards do not offer statistics at AS-level.

$5 \%$ and $22 \%$ respectively. This suggests that these three subjects were in fact the equivalent of main mathematics for the Joint Matriculation Board. Therefore, we recoded them as 'main' in our analysis. We compared models based on two sets of data including and excluding PA, PS and PM and found little difference in the results of the analyses.

Owing to missing establishment-type codes, 78 entries have also been excluded. We thus obtain a data set of 59256 entries on 52587 students from 2592 institutions with A- and AS-level subjects main, pure, applied and further mathematics. Since the A- and AS-scores are on different scales with different distributions we shall keep them separate in the following analyses, in contrast with the normal practice of combining them into a single score.

Among the 52587 students, 6541 had double mathematics and 64 had triple mathematics entries. We have calculated the raw correlation coefficients on the basis of only the pairs shown in Table 2. Because the AS-level entries are small in number for most combinations we have confined the calculations to A-level entries only.

Table 3 shows the subgroup means and standard deviations of the four mathematics scores by combination of subject. Here the combination $\mathrm{C} 1$ is for students who did courses on A-level main mathematics combined with A-level further mathematics and possibly other A-level mathematics subjects. This group of students had scores that were higher than average for both main and further mathematics A-level. Likewise, the third combination, denoted by $\mathrm{C} 3$, is for students who took A-level main combined with AS-level further mathematics. This combination also produced, on average, higher scores on A-level main mathematics. The students taking combination C5, pure plus applied 
Table 2. Number of students with single A-level mathematics (on the diagonal) and double-mathematics entries (off diagonal) $\dagger$

\begin{tabular}{|crrrr|}
\hline & $M$ & $P$ & $A$ & $F$ \\
\hline & & & & \\
$\mathrm{M}$ & 40800 & & & \\
$\mathrm{P}$ & $13(0.83)$ & 273 & 94 & 73 \\
$\mathrm{~A}$ & $10(0.25)$ & $278(0.63)$ & 0 & \\
$\mathrm{~F}$ & $4310(0.60)$ & $12(0.99)$ & & \\
\end{tabular}

$\dagger$ Pairwise correlation coefficients of responses are given in parentheses. The abbreviations are defined in Table 1.

mathematics and possibly more, also had higher scores on average for both pure and applied mathematics. This suggests that these three combinations were common choices for more able students. Students taking the A-level main and an additional AS-paper other than the further mathematics paper (indicated by $\mathrm{C} 4$ in Table 3) had rather lower scores on average for main mathematics, suggesting that this combination was a choice for the less able students. It is this 'informative' choice of combinations which implies non-random missingness that is the main focus of this paper.

Table 3. Mean scores of students by course combination

\begin{tabular}{|c|c|c|c|c|c|}
\hline \multirow[t]{2}{*}{ Subject } & \multicolumn{2}{|c|}{ Results for A-level } & \multirow[t]{2}{*}{ Subject } & \multicolumn{2}{|c|}{ Results for AS-level } \\
\hline & Students & Mean & & Students & Mean \\
\hline \multicolumn{6}{|l|}{ Main } \\
\hline Alone & 40800 & $5.54(3.29)$ & Alone & 3906 & $1.23(1.48)$ \\
\hline+ A-level $\mathrm{F}+$ possibly more $(\mathrm{C} 1)$ & 4314 & $9.45(1.39)$ & + at least 1 A-level (C6) & 24 & $3.38(1.95)$ \\
\hline+ A-level others but no F (C2) & 27 & $7.70(2.76)$ & + at least 1 AS-level (no A) & 18 & $1.18(1.59)$ \\
\hline+ AS-level F + more (C3) & 1560 & $8.68(2.04)$ & Overall & 3948 & $1.23(1.49)$ \\
\hline + AS-level others but no F (C4) & 305 & $3.34(3.82)$ & & & \\
\hline Overall & 47006 & $5.99(3.37)$ & & & \\
\hline \multicolumn{6}{|l|}{ Pure } \\
\hline Alone & 273 & $5.96(3.49)$ & Alone & 407 & $1.10(1.49)$ \\
\hline+ A-level A + possibly more (C5) & 286 & $9.23(1.66)$ & + at least 1 A-level & 256 & $1.60(1.39)$ \\
\hline+ AS-level A + more & 52 & $7.77(3.11)$ & + at least 1 AS-level (no A) & 3 & $0.96(1.40)$ \\
\hline+ AS-level others but no A & 29 & $6.50(3.30)$ & Overall & 666 & $1.27(1.46)$ \\
\hline Overall & 640 & $7.60(3.19)$ & & & \\
\hline \multicolumn{6}{|l|}{ Applied } \\
\hline Alone & 94 & $3.62(2.94)$ & Alone & 394 & $1.44(1.46)$ \\
\hline+ A-level $\mathrm{P}+$ possibly more $(\mathrm{C} 5)$ & 286 & $8.51(2.17)$ & + at least 1 A-level (C7) & 173 & $2.46(1.81)$ \\
\hline+ AS-level P + more & 7 & $4.86(3.44)$ & + at least 1 AS-level (no A) & 18 & $1.94(1.95)$ \\
\hline+ AS-level others but no P & 12 & $5.47(4.44)$ & Overall & 585 & $1.73(1.58)$ \\
\hline Overall & 399 & $7.26(3.22)$ & & & \\
\hline \multicolumn{6}{|l|}{ Further } \\
\hline Alone & 73 & $8.66(2.24)$ & Alone & 35 & $3.17(1.72)$ \\
\hline+ A-level $\mathrm{M}+$ possibly more $(\mathrm{C} 1)$ & 4314 & $7.54(2.99)$ & + at least 1 A-level & 1572 & $2.97(1.76)$ \\
\hline+ A-level others but no M & 17 & $8.48(2.94)$ & + at least 1 AS-level (no A) & 1 & \\
\hline Overall & 4404 & $7.55(2.98)$ & Overall & 1608 & $2.97(1.76)$ \\
\hline
\end{tabular}

$\dagger$ Standard deviations are given in parentheses; the abbreviations are defined in Table 1. 
Adjusting for the GCSE results can be expected to move our analysis nearer to the assumption of missingness conditionally (given GCSE result) at random, since GCSE results are correlated with overall ability. We would, however, expect other factors, such as school examination entry policies, also to be associated with the responses, but we have no information on these.

Our basic general proposal is to fit separate terms for each observed combination. We have chosen those combinations where the combination mean is substantially different from the overall mean for the subject. This procedure adjusts the mean values for each response for overall differences in the choice of subjects. It is still possible that there are interactions between combinations taken and other predictor variables such as gender and GCSE result and we shall explore this possibility. Because of possible institutional effects we shall also fit models where we allow the combination adjustment effects to vary randomly across institutions.

\section{Analytical strategies}

The following substantive questions are of interest.

(a) What are the relationships between the four mathematics options at institution level? In other words, do institutions that do well in one mathematics option tend to do well in other options? Do institutions that do well with an A-level option also tend to do well in the same option at AS-level?

(b) For students taking particular combinations of options, does the performance for different options vary across institutions? What is the institution level relationship between the different mathematics subjects for students taking particular combinations of different options?

(c) How are the effects of the predictor variables GCSE average score, GCSE mathematics score, gender, examination board and institution types associated with the average performance of students taking different options or taking particular combinations of options?

First, we fit a single-level model with the combinations identified in Table 3 . The results are compared with the simple multivariate model assuming missingness of responses at random for A- and AS-level scores separately. For simplicity, no covariates are fitted at this step and the single-level model is compared with the raw data.

Then we extend the proposed multivariate multilevel model to eight responses for A- and AS-level scores jointly, including the main effects for other covariates, the GCSE scores and gender. We also explore the fixed and random effects of the combinations of options in the model proposed, and interactions between the combinations and the covariates. This allows us to compare effects of covariates on any mathematics subject between A- and AS-levels, and to estimate the relationship of mathematical outcomes between A- and AS-levels within institution.

We use the original point scores, rather than for example a transformation to normality. This retains the familiar scale for easy interpretation. We have compared the residual distributions for each type of mathematics with the raw point score and the normally transformed score. Results based on the conditional model suggest that the assumption of normality for both A- and AS-level raw point scores is acceptable. 


\section{Some basic multivariate models}

Let $j$ indicate institution, $i$ indicate student and $h(=1,2,3,4$; main, pure, applied and further mathematics respectively) the paper chosen. This gives a three-level data structure: papers nested within students nested within institutions.

For a score on the $h$ th paper for the $i$ th student in the $j$ th institution, the simplest multilevel model, without adjusting for any covariate, is a fixed intercept for the paper, an institution random effect $v_{h, j}$ and an individual random effect $u_{h, i j}$,

$$
\begin{gathered}
y_{h, i j}=\beta_{h}+v_{h, j}+u_{h, i j}, \\
\left(v_{1, j}, v_{2, j}, v_{3, j}, v_{4, j}\right)^{\mathrm{T}} \sim \operatorname{MVN}\left(0, \Omega_{v}\right) \\
\left(u_{1, i j}, u_{2, i j}, u_{3, i j}, u_{4, i j}\right)^{\mathrm{T}} \sim \operatorname{MVN}\left(0, \Omega_{u}\right) \\
\Omega_{v}=\left(\begin{array}{cccc}
\sigma_{v 1}^{2} & \\
\sigma_{v 12} & \sigma_{v 2}^{2} & \\
\sigma_{v 13} & \sigma_{v 23} & \sigma_{v 3}^{2} & \\
\sigma_{v 14} & \sigma_{v 24} & \sigma_{v 34} & \sigma_{v 4}^{2}
\end{array}\right), \quad \Omega_{u}=\left(\begin{array}{cccc}
\sigma_{u 1}^{2} & & & \\
\sigma_{u 12} & \sigma_{u 2}^{2} & & \\
\sigma_{u 13} & \sigma_{u 23} & \sigma_{u 3}^{2} & \\
\sigma_{u 14} & \sigma_{u 24} & \sigma_{u 34} & \sigma_{u 4}^{2}
\end{array}\right) .
\end{gathered}
$$

Not every element in $\Omega_{u}$ can be estimated because of the amount of missing data in some pairs. We constrain the model to estimate only the covariance for the pairs of main and further, applied and pure mathematics for A-level results at student level and some different pairs for AS-level results. For simplicity, we first fit a simpler version of model 1 without the institution random effects, i.e. we fit $y_{h, i}=\beta_{h}+u_{h, i}$ with only covariances $\sigma_{u_{14}}$ and $\sigma_{u_{23}}$ being fitted for A-level scores, and $\sigma_{u_{12}}, \sigma_{u_{13}}$ and $\sigma_{u_{23}}$ fitted for AS-level scores. The results are listed in column A in Table 4.

To allow for the differences that are associated with the choice of option, we introduce, in addition to the fixed part of the model, dummy variables for combinations of options derived from exploratory analyses of Table 3, along with separate variances for combinations $\mathrm{C} 1$ and $\mathrm{C} 5$ of A-level results. We first present separate analyses for A- and AS-level scores. The model for A-level scores, ignoring the institution level for simplicity, may be written as

$$
\begin{gathered}
y_{h, i}=\beta_{h, i} \quad(h=1, \ldots, 4), \\
\beta_{1, i}=\beta_{1}+u_{1, i}+\left(\alpha_{1}+u_{\mathrm{C} 1, i}\right) \mathrm{C} 1_{i}+\alpha_{2} \mathrm{C}_{i}+\alpha_{3} \mathrm{C}_{i}+\alpha_{4} \mathrm{C} 4_{i}, \\
\beta_{2, i}=\beta_{2}+u_{2, i}+\left(\alpha_{5}+u_{\mathrm{C} 5, i}\right) \mathrm{C} 5_{i} \\
\beta_{3, i}=\beta_{3}+u_{3, i}, \\
\beta_{4, i}=\beta_{4}+u_{4, i}, \\
\left(u_{1, i}, u_{2, i}, u_{3, i}, u_{4, i}, u_{\mathrm{C} 1, i}, u_{\mathrm{C} 5, i}\right)^{\mathrm{T}} \sim \operatorname{MVN}\left(0, \Omega_{u}\right) .
\end{gathered}
$$

Following the procedure for modelling complex variances (Rasbash et al., 2000), we set $\sigma_{u \mathrm{C} 1}^{2}=\sigma_{u \mathrm{C} 5}^{2}=0$. We also assume that $\operatorname{cov}\left(u_{\mathrm{C} 1, i}, u_{\mathrm{C} 5, i}\right)=0$ since the combinations are measured at the student level and students take only one of the combinations $\mathrm{C} 1$ or $\mathrm{C} 5$. C1-C5 are as defined in Table 3. Note that we do not need to fit combination effects for the applied and further mathematics responses, since model (2) is adequate in terms of agreement with the raw data.

In the variance-covariance structure we assume additional random coefficients only for students who did the combinations $\mathrm{C} 1$ and $\mathrm{C} 5$. Thus for example the variance for main 
Table 4. Estimates of the A- and AS-level mathematics scores for the basic multivariate models $\dagger$

\begin{tabular}{|c|c|c|c|c|c|c|}
\hline \multirow[t]{2}{*}{ Fixed effect } & \multicolumn{2}{|c|}{$\begin{array}{l}\text { A, no combinations } \\
\text { fitted }\end{array}$} & \multicolumn{2}{|c|}{$\begin{array}{l}B, \text { combinations } \\
\text { fitted }\end{array}$} & \multicolumn{2}{|c|}{$\begin{array}{l}C, \text { combinations }+ \text { random } \\
\text { effects at institution level }\end{array}$} \\
\hline & A-level & AS-level & A-level & AS-level & A-level & AS-level \\
\hline Main, $\beta_{1}$ & $5.99(0.016)$ & $1.24(0.024)$ & $5.53(0.016)$ & $1.22(0.024)$ & $5.28(0.032)$ & $1.22(0.033)$ \\
\hline Pure, $\beta_{2}$ & $7.29(0.120)$ & $1.27(0.056)$ & $6.28(0.186)$ & $1.27(0.056)$ & $6.42(0.206)$ & $1.24(0.071)$ \\
\hline Applied, $\beta_{3}$ & $6.34(0.149)$ & $1.73(0.067)$ & $7.26(0.161)$ & $1.45(0.076)$ & $7.24(0.227)$ & $1.29(0.108)$ \\
\hline Further, $\beta_{4}$ & $3.39(0.041)$ & $2.91(0.044)$ & $7.55(0.045)$ & $2.97(0.044)$ & $6.74(0.077)$ & $2.86(0.057)$ \\
\hline $\mathrm{A}-\mathrm{C} 1, \alpha_{1}$ & & & $3.93(0.026)$ & & $3.70(0.028)$ & \\
\hline $\mathrm{A}-\mathrm{C} 2, \alpha_{2}$ & & & $1.81(0.375)$ & & $2.46(0.369)$ & \\
\hline $\mathrm{A}-\mathrm{C} 3, \alpha_{3}$ & & & $3.15(0.084)$ & & $3.03(0.079)$ & \\
\hline $\mathrm{A}-\mathrm{C} 4, \alpha_{4}$ & & & $-1.38(0.139)$ & & $-1.18(0.147)$ & \\
\hline $\mathrm{A}-\mathrm{C} 5, \alpha_{5}$ & & & $2.34(0.216)$ & & $2.09(0.228)$ & \\
\hline AS-C6, $\alpha_{6}$ & & & & $2.11(0.32)$ & & $2.27(0.33)$ \\
\hline AS $-\mathrm{C} 7, \alpha_{7}$ & & & & $0.97(0.14)$ & & $1.13(0.17)$ \\
\hline \multicolumn{7}{|c|}{ Institution level } \\
\hline$\sigma_{v 1}^{2}$ & & & & & $1.74(0.07)$ & $0.69(0.06)$ \\
\hline$\sigma_{v 2}^{2}$ & & & & & $2.27(0.39)$ & $0.85(0.14)$ \\
\hline$\sigma_{v 3}^{2}$ & & & & & $5.91(0.97)$ & $1.09(0.18)$ \\
\hline$\sigma_{v 4}^{2}$ & & & & & $5.93(0.31)$ & $1.05(0.12)$ \\
\hline$\sigma_{v 12}$ & & & & & $1.16(0.20)$ & $0.24(0.12)$ \\
\hline$\sigma_{v 13}$ & & & & & $1.76(0.32)$ & $0.16(0.15)$ \\
\hline$\sigma_{v 14}$ & & & & & $2.92(0.13)$ & $0.44(0.08)$ \\
\hline$\sigma_{v 23}$ & & & & & $3.41(0.57)$ & $0.02(0.20)$ \\
\hline$\sigma_{v 24}$ & & & & & $1.98(0.43)$ & $0.19(0.20)$ \\
\hline$\sigma_{v 34}$ & & & & & $3.04(0.69)$ & $0.50(0.19)$ \\
\hline \multicolumn{7}{|l|}{ Student level } \\
\hline & $11.37(0.07)$ & $2.22(0.05)$ & $10.55(0.07)$ & $2.19(0.05)$ & $8.73(0.06)$ & $1.55(0.04)$ \\
\hline$\sigma_{u 2}^{2}$ & $10.48(0.56)$ & $2.13(0.12)$ & $12.30(0.92)$ & $2.13(0.12)$ & $9.56(0.78)$ & $1.27(0.10)$ \\
\hline$\sigma_{u 3}^{2}$ & $13.85(0.83)$ & $2.68(0.16)$ & $10.35(0.73)$ & $2.49(0.15)$ & $5.05(0.43)$ & $1.52(0.11)$ \\
\hline$\sigma_{u 4}^{2}$ & $22.50(0.34)$ & $3.11(0.11)$ & $8.89(0.19)$ & $3.11(0.11)$ & $6.95(0.16)$ & $2.09(0.09)$ \\
\hline$\sigma_{u 12}$ & & $1.42(0.28)$ & & $1.22(0.34)$ & & \\
\hline$\sigma_{u 13}$ & & $0.88(0.49)$ & & $0.71(0.49)$ & & \\
\hline$\sigma_{u 14}$ & $13.79(0.15)$ & & $2.45(0.07)$ & & $2.18(0.07)$ & \\
\hline$\sigma_{u 23}$ & $10.72(0.62)$ & $1.60(0.40)$ & $5.12(0.44)$ & $1.63(0.34)$ & $2.43(0.27)$ & \\
\hline$\sigma_{u 1 \mathrm{Cl}}$ & & & $-4.31(0.04)$ & & $-3.41(0.04)$ & \\
\hline$\sigma_{u 2 \mathrm{C} 5}$ & & & $-4.09(0.49)$ & & $-3.53(0.41)$ & \\
\hline $\begin{array}{l}-2 \text { log- } \\
\text { likelihood }\end{array}$ & 273081.2 & 25346.43 & 262158.1 & 25261.64 & 256748.0 & 24451.89 \\
\hline
\end{tabular}

†Standard errors are given in parentheses.

mathematics for the combination $\mathrm{C} 1$ is given by $\sigma_{u 1}^{2}+2 \sigma_{u 1 \mathrm{C} 1}$ and that for pure mathematics from the combination $\mathrm{C} 5$ is given by $\sigma_{u 2}^{2}+2 \sigma_{u 2 \mathrm{C} 2}$. The covariance between options main and further is assumed the same, for students taking the combination $\mathrm{C} 1$ as for other combinations. The covariance between options pure and applied is assumed to be the same for the combination $\mathrm{C} 5$ as for the other combinations. Thus the correlation between main and further mathematics for those taking $\mathrm{C} 1$ is $\sigma_{u 14} / \sqrt{ }\left\{\left(\sigma_{u 1}^{2}+2 \sigma_{u 1 \mathrm{C} 1}\right) \sigma_{u 4}^{2}\right\}$ etc.

The student level covariance matrix is 


$$
\Omega_{u}=\left(\begin{array}{cccc}
\sigma_{u 1}^{2} & & & \\
& \sigma_{u 2}^{2} & & \\
& \sigma_{u 23} & \sigma_{u 3}^{2} & \\
\sigma_{u 14} & & & \sigma_{u 4}^{2} \\
\sigma_{u 1 \mathrm{C} 1} & & &
\end{array}\right)
$$

The extension of the model to a multilevel structure, with institutions at the highest level, is straightforward with the standard assumption of the multivariate normal distribution among higher level units.

Estimates for this model are listed in column B in Table 4. The multilevel version including the institution random effects $v_{h, j}$ is presented in column $\mathrm{C}$ in Table 4.

We can obtain predictions from Table 4 for the mean for main mathematics as the weighted sum from model $B$, using observed sample sizes, estimates of $\beta_{1}$ and $\alpha_{1} \sim \alpha_{4}$; that for pure mathematics is the weighted sum of $\beta_{2}$ and $\alpha_{5}$. The estimated between-student standard deviation can be calculated correspondingly. Similarly, estimates of overall means and standard deviations for the AS-level options can be obtained. We compare the estimates for models in columns $\mathrm{A}$ and $\mathrm{B}$ in Table 4 with the raw data in Table 5.

For A-levels we see that it is important to adjust for the options chosen in order to represent the actual score pattern. This is the case for both the fixed and the random parameters. For AS-levels, adjusting for the two options chosen is less important, suggesting a less pronounced choice of option policy.

The multilevel model which includes institutional effects gives correlation coefficients for A-levels between main and further, pure and applied mathematics at student level as 0.60 and 0.68 , and 0.93 and 0.91 at the institution level. Thus the average performance by institutions on one A-level mathematics subject is highly correlated with performance in other subjects.

Table 5. Comparison between models and raw data using results from Table $4 \dagger$

\begin{tabular}{|c|c|c|c|c|c|c|}
\hline \multirow[t]{2}{*}{ Subject } & \multicolumn{3}{|c|}{ Results for A-level } & \multicolumn{3}{|c|}{ Results for AS-level } \\
\hline & $\begin{array}{c}\text { Mean, } \\
\text { raw data }\end{array}$ & $\begin{array}{l}\text { Estimate, no } \\
\text { adjustment for } \\
\text { combinations }\end{array}$ & $\begin{array}{c}\text { Estimate, } \\
\text { adjusted for } \\
\text { combinations }\end{array}$ & $\begin{array}{c}\text { Mean, } \\
\text { raw data }\end{array}$ & $\begin{array}{c}\text { Estimate, no } \\
\text { adjustment for } \\
\text { combinations }\end{array}$ & $\begin{array}{c}\text { Estimate, } \\
\text { adjusted for } \\
\text { combinations }\end{array}$ \\
\hline M & $5.99(3.37)$ & $5.99(3.37)$ & $5.99(3.13)$ & $1.23(1.49)$ & $1.24(1.48)$ & $1.22(1.48)$ \\
\hline $\mathrm{P}$ & $7.60(3.19)$ & $7.29(3.24)$ & $7.33(2.93)$ & $1.27(1.46)$ & $1.27(1.46)$ & $1.28(1.46)$ \\
\hline A & $7.26(3.20)$ & $6.34(3.72)$ & $7.26(3.23)$ & $1.73(1.64)$ & $1.73(1.64)$ & $1.73(1.58)$ \\
\hline $\mathrm{F}$ & $7.55(2.98)$ & $3.39(4.73)$ & $7.55(2.98)$ & $2.97(1.76)$ & $2.91(1.76)$ & $2.98(1.76)$ \\
\hline \multicolumn{7}{|l|}{ Correlation } \\
\hline $\mathrm{M}$ versus $\mathrm{P}$ & $0.83(n=13)$ & & & $0.64(n=15)$ & 0.65 & 0.57 \\
\hline $\mathrm{M}$ versus $\mathrm{A}$ & $0.25(n=10)$ & & & $0.37(n=17)$ & 0.36 & 0.30 \\
\hline $\mathrm{M}$ versus $\mathrm{F}$ & $0.60(n=4310)$ & 0.86 & $0.53(\mathrm{C} 1)$ & - & - & - \\
\hline $\mathrm{P}$ versus A & $0.63(n=278)$ & 0.89 & $0.78(\mathrm{C} 5)$ & $0.82\left(n^{+}=7\right)$ & $0.67^{+}$ & $0.71^{*}$ \\
\hline $\mathrm{P}$ versus $\mathrm{F}$ & $0.99(n=12)$ & & & $0.60(n=9)$ & $-t$ & 一 \\
\hline A versus $\mathrm{F}$ & $-\neq$ & & & $0.83(n=5)$ & $-t$ & $-t$ \\
\hline
\end{tabular}

$\dagger$ Estimated standard deviations are given in parenthesis; the abbreviations are defined in Table 1.

† Not applicable. 


\section{Modelling A- and AS-level together and adjusting for General Certificate of Secondary Education results}

We now fit A- and AS-level scores in a single model together with various other predictors, including GCSE scores. The polynomials fitted for the GCSE variables are similar to those fitted by Yang and Woodhouse (2001). All GCSE scores are centred at their sample means. The estimates for the fixed parameters are given in Table 6 and those for the random parameters in Table 7. The term for combination $\mathrm{C} 2$ has been omitted because of the small number of students.

On the basis of the GCSE-adjusted model, we can summarize our findings as follows.

\subsection{Gender}

The results show that compared with male students, at the average GCSE score, females do worse. Among the AS-options, gender effects were less pronounced, and a single AS-level gender effect was estimated. There is a quadratic interaction effect between gender and the GCSE average score, showing that girls have their worst performance at a GCSE average score of about 4 and improve both for lower and for higher GCSE scores. Achievement on main mathematics for females is less variable than for male students, but the reverse is true for further mathematics. For AS-level data, achievements on both main and further mathematics for females are more variable than for males.

\subsection{Age}

Significant age effects are present only for main and further mathematics for both A- and ASlevels, scores decreasing with age. For pure and applied mathematics, no significant age effect is found.

\subsection{Institution type}

Before adjusting for the two GCSE scores, institution type showed large effects with an advantage to the selective, independent and sixth form institutions. Having adjusted for GCSE results, the effects of maintained selective and modern schools as well as grammar modern schools were very small and have been combined with those of the base category, maintained comprehensive. There is just a small advantage for the sixth form colleges and other independent schools, and a small disadvantage for further education colleges. Independent selective schools show a small advantage for A-level further mathematics. No differential institutional effects are found for AS-level. See also Yang and Woodhouse (2001) for a further discussion.

\subsection{Examination board}

The examination boards had different means for the different mathematics options, although all the other five boards did better on A-level main mathematics compared with the Associated Examining Board. The Cambridge board and Joint Matriculation Board did significantly better on both main and further mathematics for A-level. For the AS-subjects, the Cambridge board had a significantly positive effect for main mathematics only. There is a tendency that boards that had a higher mean on an A-level subject also had a higher mean on the same subject at AS-level. In some cases the differences for AS-level subjects were not significant because of the small number of students in those subjects. There are few notable 
Table 6. Parameter estimates for the fixed effects with and without adjusting for GCSE results†

\begin{tabular}{|c|c|c|c|c|c|}
\hline Variable & $\begin{array}{c}\text { Without } \\
\text { adjusting } \\
\text { for GCSE }\end{array}$ & $\begin{array}{c}\text { Adjusted } \\
\text { for GCSE }\end{array}$ & Variable & $\begin{array}{c}\text { Without } \\
\text { adjusting } \\
\text { for GCSE }\end{array}$ & $\begin{array}{l}\text { Adjusted } \\
\text { for GCSE }\end{array}$ \\
\hline \multicolumn{6}{|l|}{ Main effects } \\
\hline Intercept & & & $\mathrm{OXF}-\mathrm{A}-\mathrm{M}$ & $0.648(0.255)$ & $0.487(0.185)$ \\
\hline $\mathrm{A}-\mathrm{M}$ & $4.183(0.089)$ & $5.155(0.067)$ & $\mathrm{OXF}-\mathrm{A}-\mathrm{P}$ & $2.164(1.021)$ & $1.246(0.719)$ \\
\hline $\mathrm{A}-\mathrm{P}$ & $5.949(0.280)$ & $6.051(0.209)$ & $\mathrm{OXF}-\mathrm{A}-\mathrm{F}$ & $-2.801(0.661)$ & $-3.003(0.568)$ \\
\hline $\mathrm{A}-\mathrm{A}$ & $5.750(0.319)$ & $5.875(0.192)$ & $\mathrm{OXF}-\mathrm{AS}-\mathrm{M}$ & $0.318(0.288)$ & $-0.006(0.218)$ \\
\hline $\mathrm{A}-\mathrm{F}$ & $5.256(0.233)$ & $4.803(0.202)$ & $\mathrm{OXF}-\mathrm{AS}-\mathrm{P}$ & $2.944(0.547)$ & $1.595(0.400)$ \\
\hline AS-M & $0.804(0.162)$ & $1.561(0.126)$ & $\mathrm{OXF}-\mathrm{AS}-\mathrm{F}$ & $0.445(0.947)$ & $-0.365(0.815)$ \\
\hline AS-P & $0.964(0.100)$ & $1.556(0.078)$ & $\mathrm{JMB}-\mathrm{A}-\mathrm{M}$ & $0.701(0.100)$ & $0.919(0.073)$ \\
\hline AS $-\mathrm{A}$ & $0.578(0.215)$ & $1.303(0.172)$ & $\mathrm{JMB}-\mathrm{A}-\mathrm{F}$ & $1.330(0.258)$ & $1.378(0.224)$ \\
\hline AS-F & $2.269(0.319)$ & $1.780(0.279)$ & JMB-AS-M & $0.153(0.170)$ & $0.194(0.130)$ \\
\hline Combinations & & & $\mathrm{JMB}-\mathrm{AS}-\mathrm{F}$ & $0.516(0.335)$ & $0.339(0.292)$ \\
\hline $\mathrm{A}-\mathrm{Cl}$ & $3.660(0.047)$ & $2.796(0.054)$ & OXCAMB-A-M & $0.998(0.108)$ & $0.865(0.078)$ \\
\hline $\mathrm{A}-\mathrm{C} 3$ & $3.012(0.076)$ & $2.239(0.066)$ & OXCAMB-A-P & $0.790(1.038)$ & $0.635(0.784)$ \\
\hline $\mathrm{A}-\mathrm{C} 4$ & $-1.732(0.171)$ & $-1.897(0.162)$ & OXCAMB-A-A & $2.867(1.723)$ & $1.558(1.313)$ \\
\hline $\mathrm{A}-\mathrm{C} 5$ & $1.895(0.247)$ & $1.486(0.204)$ & OXCAMB-A-F & $1.364(0.270)$ & $0.937(0.232)$ \\
\hline $\mathrm{AS}-\mathrm{C} 6$ & $2.338(0.312)$ & $1.788(0.250)$ & OXCAMB-AS-M & $0.524(0.175)$ & $0.365(0.134)$ \\
\hline $\mathrm{AS}-\mathrm{C} 7$ & $1.603(0.204)$ & $0.754(0.166)$ & OXCAMB-AS-P & $-0.044(0.316)$ & $0.294(0.244)$ \\
\hline \multicolumn{3}{|c|}{ Gender (female - male) } & OXCAMB-AS-A & $0.750(0.242)$ & $0.686(0.191)$ \\
\hline $\mathrm{A}-\mathrm{M}$ & $0.416(0.031)$ & $-0.412(0.029)$ & OXCAMB-AS-F & $0.459(0.336)$ & $0.422(0.293)$ \\
\hline $\mathrm{A}-\mathrm{P}$ & $-0.337(0.252)$ & $-0.839(0.209)$ & GCSE average & & \\
\hline $\mathrm{A}-\mathrm{A}$ & $-0.195(0.310)$ & $-0.840(0.232)$ & A-GA & & $1.878(0.065)$ \\
\hline $\mathrm{A}-\mathrm{F}$ & $0.559(0.091)$ & $-0.639(0.086)$ & $\mathrm{A}-\mathrm{GA}^{2}$ & & $0.223(0.021)$ \\
\hline AS & $0.085(0.103)$ & $-0.236(0.086)$ & $\mathrm{A}-\mathrm{GA}^{3}$ & & $-0.198(0.013)$ \\
\hline Age & & & $\mathrm{A}-\mathrm{GA}^{4}$ & & $-0.028(0.002)$ \\
\hline $\mathrm{A}-\mathrm{M}$ & $-0.017(0.004)$ & $-0.049(0.003)$ & AS-GA & & $0.705(0.027)$ \\
\hline $\mathrm{A}-\mathrm{P}$ & $-0.001(0.029)$ & $-0.020(0.024)$ & $\mathrm{AS}-\mathrm{GA}^{2}$ & & $0.217(0.021)$ \\
\hline $\mathrm{A}-\mathrm{A}$ & $0.007(0.035)$ & $-0.017(0.029)$ & $\mathrm{AS}-\mathrm{GA}^{3}$ & & $0.011(0.005)$ \\
\hline $\mathrm{A}-\mathrm{F}$ & $-0.032(0.011)$ & $-0.078(0.010)$ & GCSE mathematics & & \\
\hline AS-M & $-0.006(0.006)$ & $-0.018(0.005)$ & $\mathrm{A}-\mathrm{GM}$ & & $1.344(0.020)$ \\
\hline AS-P & $-0.033(0.014)$ & $-0.021(0.012)$ & $\mathrm{A}-\mathrm{GM}^{2}$ & & $0.078(0.021)$ \\
\hline AS-A & $0.017(0.017)$ & $0.005(0.014)$ & $\mathrm{A}-\mathrm{GM}^{3}$ & & $-0.023(0.003)$ \\
\hline AS-F & $-0.040(0.011)$ & $-0.041(0.010)$ & AS-GM & & $0.575(0.029)$ \\
\hline \multicolumn{3}{|c|}{ Institution (base, MC) } & $\mathrm{AS}-\mathrm{GM}^{2}$ & & $0.161(0.025)$ \\
\hline Msel & $0.631(0.099)$ & & $\mathrm{AS}-\mathrm{GM}^{3}$ & & $0.010(0.003)$ \\
\hline Mmodern & $-0.865(0.252)$ & & Institution level & & \\
\hline GMcomp & $-0.010(0.060)$ & $0.055(0.045)$ & Aggregated GA & & $0.148(0.060)$ \\
\hline GMsel & $0.644(0.084)$ & $-0.006(0.066)$ & Aggregated GM & & $-0.017(0.034)$ \\
\hline GMmodern & $-0.556(0.295)$ & & & & \\
\hline Indsel & $1.230(0.055)$ & $0.060(0.048)$ & Interactions & & \\
\hline Indns & $0.138(0.154)$ & $0.208(0.119)$ & GCSE $\times$ combination & & \\
\hline 6 th form college & $0.144(0.068)$ & $0.121(0.051)$ & $\mathrm{A}-\mathrm{C} 1 \times \mathrm{GA}$ & & $-1.036(0.068)$ \\
\hline FE college & $-0.511(0.065)$ & $-0.164(0.051)$ & $\mathrm{A}-\mathrm{Cl} \times \mathrm{GA}^{2}$ & & $-0.238(0.033)$ \\
\hline Unknown & $0.656(0.196)$ & & $\mathrm{A}-\mathrm{Cl} \times \mathrm{GA}^{3}$ & & $0.099(0.024)$ \\
\hline Board (base, AFB) & & & $\mathrm{A}-\mathrm{C} 1 \times \mathrm{GM}$ & & $-0.605(0.050)$ \\
\hline Camb-A-M & $1.493(0.114)$ & $1.136(0.083)$ & $\mathrm{A}-\mathrm{Cl} \times \mathrm{GM}^{2}$ & & $-0.082(0.027)$ \\
\hline Camb-A-P & $2.438(2.401)$ & $0.893(1.765)$ & $\mathrm{A}-\mathrm{C} 3 \times \mathrm{GM}$ & & $0.460(0.169)$ \\
\hline $\mathrm{Camb}-\mathrm{A}-\mathrm{F}$ & $1.962(0.279)$ & $1.114(0.238)$ & $\mathrm{A}-\mathrm{C} 3 \times \mathrm{GM}^{2}$ & & $0.612(0.146)$ \\
\hline Camb-AS-M & $0.560(0.180)$ & $0.433(0.136)$ & $\mathrm{GA} \times \mathrm{GM}$ & & \\
\hline Camb-AS-P & $0.563(0.322)$ & $0.305(0.248)$ & A & & $-0.232(0.028)$ \\
\hline $\mathrm{Camb}-\mathrm{AS}-\mathrm{F}$ & $0.630(0.361)$ & $0.589(0.314)$ & AS & & $-0.051(0.027)$ \\
\hline LOND-A-M & $0.483(0.097)$ & $0.295(0.071)$ & GCSE $\times$ gender & & \\
\hline LOND-A-P & $0.183(0.304)$ & $-0.706(0.220)$ & Girl $\times$ GA & & $0.063(0.029)$ \\
\hline LOND-A-A & $1.678(0.392)$ & $0.286(0.236)$ & Girl $\times \mathrm{GA}^{2}$ & & $0.117(0.024)$ \\
\hline LOND $-\mathrm{A}-\mathrm{F}$ & $0.323(0.248)$ & $-0.082(0.214)$ & GCSE $\times$ subject & & \\
\hline LOND-AS-M & $-0.080(0.165)$ & $-0.159(0.126)$ & $\mathrm{A}-\mathrm{M} \times \mathrm{GA}$ & & $\begin{array}{c}0.106(0.061) \\
(\text { continued })\end{array}$ \\
\hline
\end{tabular}


Table 6 (continued)

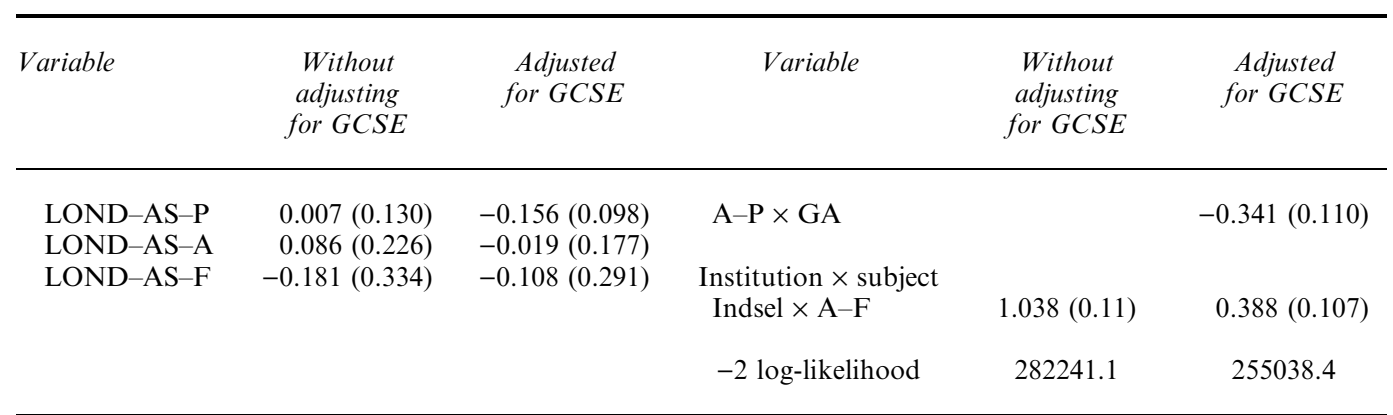

$\uparrow$ Standard errors are given in parentheses. The range of scores for GCSE mathematics (GM) and average (GA) scores is $0-8$, and they are centred on an origin of 6.25. Institution types: MC, maintained comprehensive; Msel, maintained selective; Mmodern, maintained modern; GMcomp, grant-maintained comprehensive; GMsel, grantmaintained selective; GMmodern, grant-maintained secondary modern; Indsel, independent selective; Indns, independent non-selective; FE college, further education college; other abbreviations are defined in Table 1.

changes after adjusting for GCSE scores, except in the case of the London board pure and applied mathematics results. This would suggest that the selection of examination board is only weakly associated with prior performance.

The estimates of variances and covariances in Table 7 indicate that adjusting for the main effects of the two GCSE scores reduces the institutional level variation by over half for both A- and AS-level. It also reduces considerably the variation between students. At institution level for A-level, there are high correlations between the pairs of main and further, and applied and pure mathematics. For the AS-level subjects, the institution level correlations are estimated to be small or insignificant.

We also see from Table 7 that the estimated correlation coefficients for options main, pure and further mathematics between A- and AS-levels are all around 0.30 among institutions. The numbers of institutions involved in doing each of the three subjects on both A- and AS-levels are 1212, 78 and 405 respectively. The correlation for the applied mathematics option between A- and AS-level could not be estimated owing to the relatively small number of institutions (44) that did both. The weak relationships suggest that institutions that did well on a mathematics subject at A-level were not necessarily also doing well on the same mathematics subject at AS-level.

Among students, no student in the data had scores of the same type of mathematics at both A- and AS-levels.

\section{Modelling random effects for choice of subject: A-level only}

We now allow the coefficients of the subject combination dummy variables to be random across institutions. At the student level the variance is now modelled as a function of these combinations as well as gender. For simplicity we now model only the A-level results in these analyses.

The four combination groups do not come from the same set of institutions. The combination $\mathrm{C} 1$ consists of 4314 students from 990 institutions, C3 has 1560 students from 622 institutions and combinations C4 and C5 have 305 and 286 students from 162 and 101 institutions respectively. The variances and covariances to be estimated are as follows: 


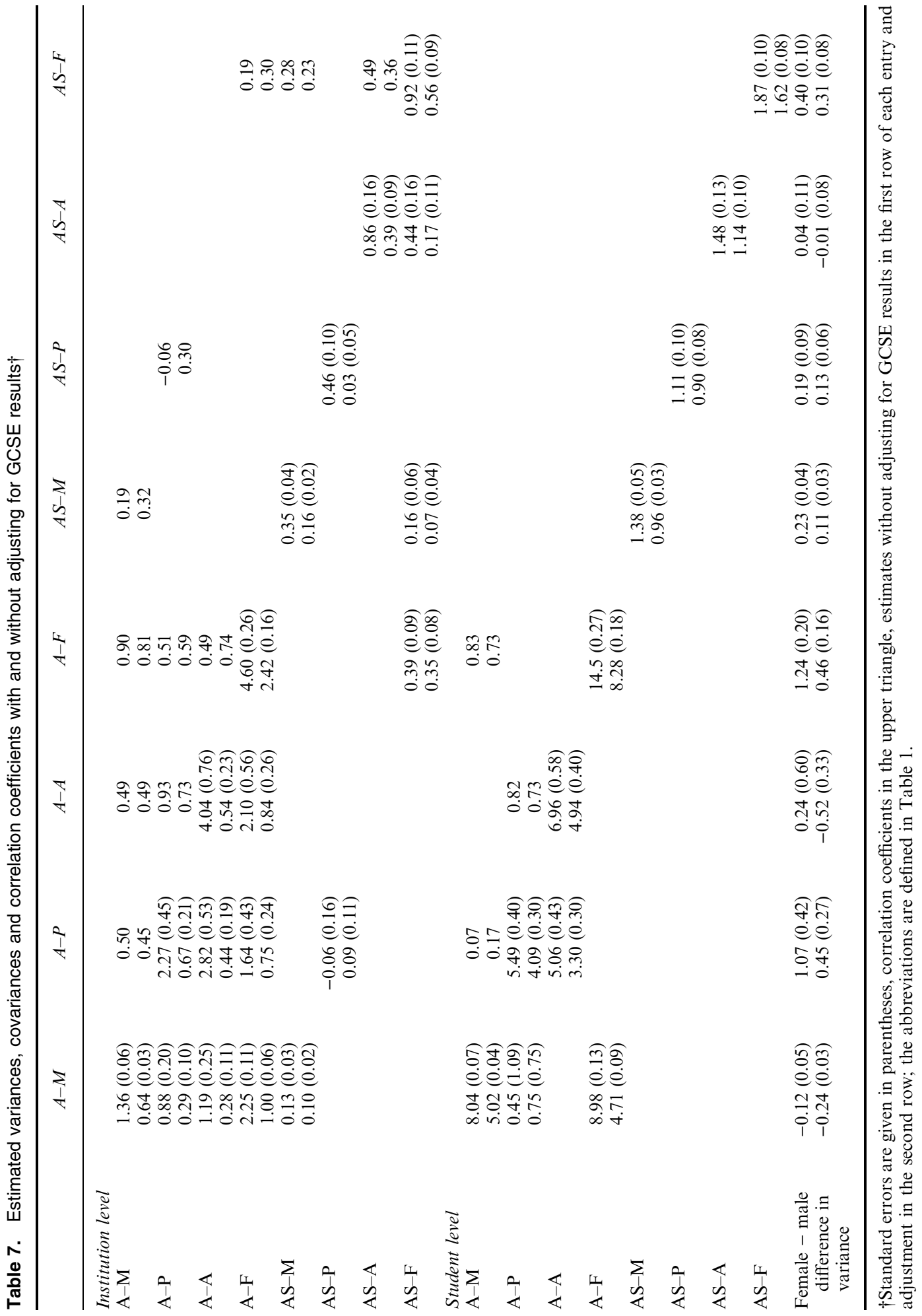




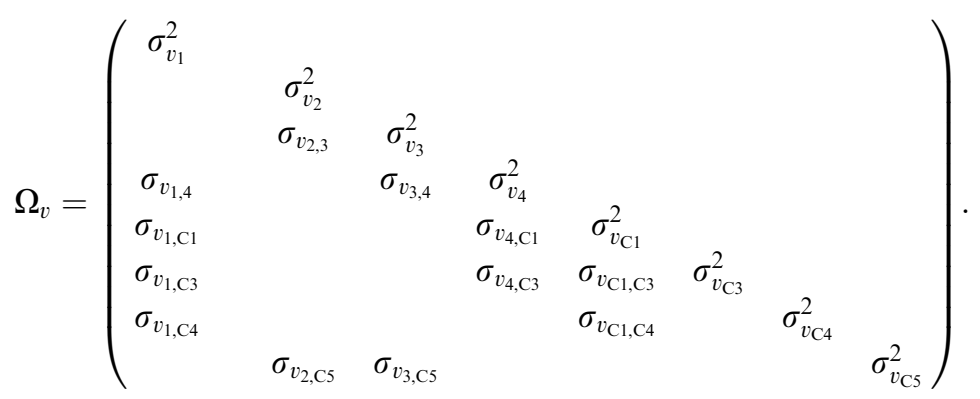

Thus, for example, the variance of main mathematics effect of the base group of students among institutions is estimated as $\sigma_{v_{1}}^{2}$, and that for the coefficient of the combination $\mathrm{C} 1$ is $\sigma_{v_{1}}^{2}+2 \sigma_{v_{1, \mathrm{C} 1}}+\sigma_{v_{\mathrm{Cl}}}^{2}$. At the institution level the covariance between the base group score effect and that for the combination $\mathrm{C} 1$ on main mathematics is $\sigma_{v_{1}}^{2}+\sigma_{v_{1, \mathrm{Cl}}}$. Thus the correlation coefficient between the base group and $\mathrm{C} 1$ combination for main mathematics is $\rho_{1, \mathrm{C} 1}=\left(\sigma_{v_{1}}^{2}+\sigma_{v_{1, \mathrm{Cl}}}\right) / \sqrt{ }\left\{\sigma_{v_{1}}^{2}\left(\sigma_{v_{1}}^{2}+2 \sigma_{v_{1, \mathrm{Cl}}}+\sigma_{v_{\mathrm{Cl}}}^{2}\right)\right\}$.

Between students, the first four random effects refer to the subjects (main, pure, applied and further mathematics), the next four to the combinations $(\mathrm{C} 1, \mathrm{C} 3, \mathrm{C} 4, \mathrm{C} 5)$ and the final combination is the gender effect (indexed by the subscript $\mathrm{g}$ ). The variance-covariance matrix is

$$
\Omega_{u}=\left(\begin{array}{cccc}
\sigma_{u_{1}}^{2} & & & \\
& \sigma_{u_{2}}^{2} & & \\
& \sigma_{u_{23}} & \sigma_{u_{3}}^{2} & \\
\sigma_{u_{14}} & & & \sigma_{u_{4}}^{2} \\
\sigma_{u_{1, \mathrm{Cl}}} & & & \\
\sigma_{u_{1, \mathrm{C} 3}} & & & \\
\sigma_{u_{1, \mathrm{C} 4}} & & & \\
\sigma_{u_{1, \mathrm{~g}}} & \sigma_{u_{2, \mathrm{C}}} & \sigma_{u_{3, \mathrm{~g}}} & \sigma_{u_{4, \mathrm{~g}}}
\end{array}\right) .
$$

The results from fitting these models are given in Tables 8 and 9 for the fixed and random parameter estimates separately. For the fixed effects, changes occur mainly in the estimates associated with further mathematics.

We shall not discuss these results in detail but it is worth noting that for main mathematics the performance of institutions for students taking combination $\mathrm{C} 1$ is much less variable with variance 0.14 , compared with 3.56 for those taking combination $\mathrm{C} 4$ and 0.76 for the base group students. As can be seen from Table 3, the mean for combination $\mathrm{C} 1$ is close to the maximum (10) so we would expect less variation among both students and institutions. Note also that the variance for those taking combination $\mathrm{C} 4$ is based on relatively small numbers and is very poorly estimated, having a standard error of 0.57 compared with standard errors of 0.02 and 0.11 for the variances that are associated with combinations $\mathrm{C} 1$ and $\mathrm{C} 3$ respectively. Also of interest is that female students for main, pure and applied mathematics show less variability than do male students, with no difference for further mathematics.

We can also compute the institution level correlations, for each subject, for those who take just that subject and those who take a particular combination. Thus, for example, the 
Table 8. Parameter estimates for the fixed effects with and without random coefficients of combinations for A-level papers $\dagger$

\begin{tabular}{|c|c|c|c|c|c|}
\hline Variable & $\begin{array}{l}\text { No random } \\
\text { coefficients } \\
\text { fitted for } \\
\text { combinations }\end{array}$ & $\begin{array}{l}\text { Random } \\
\text { coefficients } \\
\text { fitted for } \\
\text { combinations }\end{array}$ & Variable & $\begin{array}{c}\text { No random } \\
\text { coefficients } \\
\text { fitted for } \\
\text { combinations }\end{array}$ & $\begin{array}{l}\text { Random } \\
\text { coefficients } \\
\text { fitted for } \\
\text { combinations }\end{array}$ \\
\hline Main effects & & & $\mathrm{OXF}-\mathrm{M}$ & $0.452(0.176)$ & $0.400(0.164)$ \\
\hline Intercept & & & $\mathrm{OXF}-\mathrm{P}$ & $1.806(0.842)$ & $1.858(0.943)$ \\
\hline $\mathrm{M}$ & $5.208(0.064)$ & $5.261(0.061)$ & $\mathrm{OXF}-\mathrm{F}$ & $-2.983(0.558)$ & $-3.008(0.529)$ \\
\hline $\mathrm{P}$ & $5.937(0.215)$ & $5.909(0.227)$ & JMB-M & $0.780(0.069)$ & $0.637(0.064)$ \\
\hline A & $5.925(0.179)$ & $5.961(0.180)$ & JMB-F & $1.354(0.222)$ & $0.903(0.214)$ \\
\hline $\mathrm{F}$ & $4.804(0.198)$ & $5.108(0.191)$ & OXCAMB-M & $0.778(0.074)$ & $0.686(0.067)$ \\
\hline Combinations & & & OXCAMB-P & $0.467(0.800)$ & $0.511(0.817)$ \\
\hline $\mathrm{C} 1$ & $2.855(0.037)$ & $2.897(0.042)$ & OXCAMB-A & $1.145(1.301)$ & $1.367(1.308)$ \\
\hline $\mathrm{C} 3$ & $2.287(0.051)$ & $2.331(0.061)$ & OXCAMB-F & $0.918(0.229)$ & $0.563(0.220)$ \\
\hline $\mathrm{C} 4$ & $-1.948(0.194)$ & $-1.963(0.226)$ & GCSE average & & \\
\hline $\mathrm{C} 5$ & $1.630(0.193)$ & $1.699(0.220)$ & GA & $1.829(0.059)$ & $1.812(0.059)$ \\
\hline Gender (female - male) & & & $\mathrm{GA}^{2}$ & $0.233(0.021)$ & $0.229(0.020)$ \\
\hline M & $-0.412(0.028)$ & $-0.397(0.028)$ & $\mathrm{GA}^{3}$ & $-0.196(0.012)$ & $-0.193(0.012)$ \\
\hline $\mathrm{P}$ & $-0.669(0.172)$ & $-0.688(0.169)$ & $\mathrm{GA}^{4}$ & $-0.028(0.002)$ & $-0.027(0.002)$ \\
\hline A & $-0.747(0.226)$ & $-0.751(0.225)$ & GCSE mathematics & & \\
\hline $\mathrm{F}$ & $-0.621(0.086)$ & $-0.614(0.085)$ & GM & $1.339(0.021)$ & $1.343(0.021)$ \\
\hline Age & & & $\mathrm{GM}^{2}$ & $0.070(0.021)$ & $0.063(0.021)$ \\
\hline $\mathrm{M}$ & $-0.043(0.003)$ & $-0.042(0.003)$ & $\mathrm{GM}^{3}$ & $-0.025(0.003)$ & $-0.026(0.003)$ \\
\hline $\mathrm{P}$ & $-0.004(0.020)$ & $-0.007(0.020)$ & & & \\
\hline A & $-0.013(0.028)$ & $-0.016(0.028)$ & Interactions & & \\
\hline $\mathrm{F}$ & $-0.072(0.010)$ & $-0.072(0.010)$ & GCSE $\times$ combination & & \\
\hline Institution (base, MC) & & & $\mathrm{C} 1 \times \mathrm{GA}$ & $-1.115(0.051)$ & $-1.124(0.050)$ \\
\hline GMcomp & $0.177(0.059)$ & $0.164(0.054)$ & $\mathrm{Cl} \times \mathrm{GA}^{2}$ & $-0.239(0.027)$ & $-0.245(0.026)$ \\
\hline Indsel & $0.157(0.052)$ & $0.123(0.044)$ & $\mathrm{C} 1 \times \mathrm{GA}^{3}$ & $0.122(0.019)$ & $0.119(0.018)$ \\
\hline Indns & $0.393(0.163)$ & $0.401(0.156)$ & $\mathrm{C} 1 \times \mathrm{GM}$ & $-0.623(0.039)$ & $-0.608(0.039)$ \\
\hline 6 th form college & $0.174(0.072)$ & $0.100(0.056)$ & $\mathrm{C} 1 \times \mathrm{GM}^{2}$ & $-0.080(0.021)$ & $-0.085(0.020)$ \\
\hline FE college & $-0.346(0.072)$ & $-0.251(0.066)$ & $\mathrm{C} 3 \times \mathrm{GM}$ & $0.516(0.205)$ & $-0.047(0.197)$ \\
\hline Board (base, AEB) & & & $\mathrm{C} 3 \times \mathrm{GM}^{2}$ & $0.643(0.177)$ & $-0.458(0.161)$ \\
\hline CAMB-M & $1.005(0.078)$ & $0.892(0.070)$ & $\mathrm{GA} \times \mathrm{GM}$ & $-0.250(0.027)$ & $-0.242(0.027)$ \\
\hline CAMB-P & $1.250(1.944)$ & $1.354(2.031)$ & GCSE $\times$ gender & & \\
\hline CAMB-F & $1.090(0.235)$ & $0.670(0.225)$ & Girl $\times$ GA & $0.083(0.027)$ & $0.089(0.026)$ \\
\hline LOND-M & $0.250(0.067)$ & $0.263(0.061)$ & Girl $\times \mathrm{GA}^{2}$ & $0.126(0.023)$ & $0.122(0.022)$ \\
\hline LOND-P & $-0.566(0.195)$ & $-0.596(0.196)$ & GCSE $\times$ subject & & \\
\hline LOND-A & $0.298(0.223)$ & $0.277(0.225)$ & $\mathrm{M} \times \mathrm{GA}$ & $0.150(0.055)$ & $0.157(0.055)$ \\
\hline \multirow[t]{3}{*}{ LOND-F } & $-0.036(0.212)$ & $-0.174(0.205)$ & $\mathrm{P} \times \mathrm{GA}$ & $-0.446(0.102)$ & $-0.440(0.102)$ \\
\hline & & & $\begin{array}{l}\text { Institution } \times \text { subject } \\
\text { Indsel } \times F\end{array}$ & $0.387(0.109)$ & $0.370(0.106)$ \\
\hline & & & -2 log-likelihood & 231455.0 & 230654.6 \\
\hline
\end{tabular}

$\dagger$ Standard errors are given in parentheses; the abbreviations are defined in Tables 1 and 6.

institution level correlation between those taking just main mathematics and those taking combination $\mathrm{C} 1$ is

$$
(0.76-0.66) / \sqrt{ }\{0.76(0.76-2 \times 0.66+0.70)\}=0.31 .
$$

For combination $\mathrm{C} 3$ the correlation is 0.42 and for combination $\mathrm{C} 4$ it is 0.20 . The institution level correlations between those taking just further mathematics and those taking combinations $\mathrm{C} 1$ and $\mathrm{C} 3$ are estimated respectively as 1.0 and 0.68 , which is unsurprising given the definitions of these combinations. 
Table 9. Estimated variances and covariances for the model in Table $8 \dagger$

\begin{tabular}{|c|c|c|c|c|c|c|c|c|}
\hline & $M$ & $P$ & $A$ & $F$ & $C 1$ & $C 3$ & C4 & $C 5$ \\
\hline \multicolumn{9}{|c|}{ Institution level: } \\
\hline \multirow{2}{*}{$\mathrm{M}$} & $0.51(0.02)$ & & & & & & & \\
\hline & $0.76(0.03)$ & & & & & & & \\
\hline \multirow[t]{2}{*}{$\mathrm{P}$} & & $0.45(0.14)$ & & & & & & \\
\hline & & $1.07(0.46)$ & & & & & & \\
\hline \multirow[t]{2}{*}{ A } & & $0.28(0.13)$ & $0.36(0.18)$ & & & & & \\
\hline & & $0.08(0.35)$ & $0.41(0.19)$ & & & & & \\
\hline \multirow[t]{2}{*}{$\mathrm{F}$} & $0.87(0.05)$ & & $0.45(0.16)$ & $2.21(0.15)$ & & & & \\
\hline & $0.55(0.05)$ & & $0.46(0.16)$ & $1.22(0.12)$ & & & & \\
\hline \multirow[t]{2}{*}{$\mathrm{C} 1$} & - & & & - & - & & & \\
\hline & $-0.66(0.04)$ & & & $-0.37(0.06)$ & $0.70(0.05)$ & & & \\
\hline \multirow[t]{2}{*}{$\mathrm{C} 3$} & - & & & - & - & - & & \\
\hline & $-0.42(0.06)$ & & & $-0.26(0.11)$ & $0.43(0.07)$ & $0.92(0.13)$ & & \\
\hline \multirow[t]{2}{*}{$\mathrm{C} 4$} & - & & & & & - & - & \\
\hline & $-0.43(0.12)$ & & & & & $0.30(0.66)$ & $3.66(0.80)$ & \\
\hline \multirow[t]{2}{*}{ C5 } & & - & - & & & & & - \\
\hline & & $-0.99(0.54)$ & $0.25(0.38)$ & & & & & $1.42(0.77)$ \\
\hline \multicolumn{9}{|c|}{ Student levels } \\
\hline \multirow[t]{2}{*}{$\mathrm{M}$} & $5.47(0.04)$ & & & & & & & \\
\hline & $5.36(0.04)$ & & & & & & & \\
\hline \multirow[t]{2}{*}{$\mathrm{P}$} & & $7.25(0.57)$ & & & & & & \\
\hline & & $6.77(0.58)$ & & & & & & \\
\hline \multirow[t]{2}{*}{ A } & & $1.70(0.21)$ & $3.99(0.34)$ & & & & & \\
\hline & & $1.66(0.21)$ & $3.97(0.34)$ & & & & & \\
\hline \multirow[t]{2}{*}{$\mathrm{F}$} & $1.59(0.06)$ & & & $5.37(0.13)$ & & & & \\
\hline & $1.50(0.06)$ & & & $5.31(0.13)$ & & & & \\
\hline \multirow[t]{2}{*}{$\mathrm{C} 1$} & $-1.88(0.03)$ & & & & & & & \\
\hline & $-1.90(0.03)$ & & & & & & & \\
\hline \multirow[t]{2}{*}{$\mathrm{C} 3$} & $-1.27(0.05)$ & & & & & & & \\
\hline & $-1.46(0.03)$ & & & & & & & \\
\hline \multirow[t]{2}{*}{$\mathrm{C} 4$} & $1.08(0.29)$ & & & & & & & \\
\hline & $-0.27(0.24)$ & & & & & & & \\
\hline \multirow[t]{2}{*}{$\mathrm{C} 5$} & & $-2.66(0.28)$ & & & & & & \\
\hline & & $-2.45(0.29)$ & & & & & & \\
\hline \multirow[t]{2}{*}{ Gender } & $-0.22(0.03)$ & $-0.36(0.16)$ & $-0.56(0.25)$ & $-0.05(0.09)$ & & & & \\
\hline & $-0.22(0.02)$ & $-0.41(0.15)$ & $-0.60(0.24)$ & $-0.01(0.09)$ & & & & \\
\hline
\end{tabular}

$\uparrow$ Standard errors are given in parentheses; estimates without random coefficients of combinations are in the first row of each entry; those with random coefficients in the second row; the abbreviations are defined in Table 1.

†Main, $\operatorname{var}(\mathrm{C} 1)=0.76-2(0.66)+0.70=0.14, \quad \operatorname{var}(\mathrm{C} 3)=0.76-2(0.42)+0.92=0.84, \quad \operatorname{var}(\mathrm{C} 4)=0.76-$ $2(0.43)+3.66=3.56 ;$ further, $\operatorname{var}(\mathrm{C} 1)=1.22-2(0.37)+0.70=1.18, \quad \operatorname{var}(\mathrm{C} 3)=1.22-2(0.26)+0.92=$ 1.62 ; pure, $\operatorname{var}(\mathrm{C} 5)=1.07-2(0.99)+1.42=0.51$; applied, $\operatorname{var}(\mathrm{C} 5)=0.41+2(0.25)+1.42=2.33(\operatorname{var}(\mathrm{C} x)$ means the variance of those choosing the combination $\mathrm{C} x$ ).

§Main, $\operatorname{var}(\mathrm{C} 1)=5.36-2(1.90)=1.56, \quad \operatorname{var}(\mathrm{C} 3)=5.36-2(1.46)=2.44, \quad \operatorname{var}(\mathrm{C} 4)=5.36-2(0.27)=4.82$; pure, $\operatorname{var}(\mathrm{C} 5)=6.77-2(2.45)=1.87$. Estimated reduction in variance for females for each response: main, $2(0.22)=0.44$; pure, $2(0.41)=0.82$; applied, $2(0.60)=1.20$; further, $2(0.01)=0.02$.

At the student level the correlations between main and further mathematics for combination $\mathrm{C} 1$, and between pure and applied mathematics for combination $\mathrm{C} 5$ remain strong at 0.52 and 0.47 respectively. For other students the correlations are 0.28 and 0.32 .

\section{Discussion}

In this study we have shown that the choice of subject is strongly associated with performance. In multivariate response models, therefore, where not all responses are present 
as a result of a deliberate choice of response combination, we cannot assume missingness at random. We demonstrated, via a series of models of increasing complexity, that the inclusion of terms based on chosen subject combinations can provide insights into the data structure. In particular we fitted models that allow the effects of choice to vary at institution level and where the student level variation is allowed to be a function of the chosen combinations. In effect, adding terms for choice combinations makes allowance for different 'abilities', in so far as these are not adjusted for using the GCSE prior achievement measure. This approach requires spotting the patterns of missing responses correctly and reparameterizing the random parameters at levels. We have shown that the combinations of main (A-level) and further mathematics options (A- or AS-level), and also pure and applied mathematics options (A-level) are common choices for more able students. Our results suggest that for the ASlevel results the assumption of missingness at random is acceptable.

In the present context the choices of subject are made generally at the start of the course of study. In other situations, e.g. when considering the choice of questions within an examination, our approach is more problematical. In particular this will be so if the number of combinations is very large with some combinations chosen by few students. In this case, the pooling of such combinations may be acceptable.

We have shown that the A- and AS-level scores cannot be modelled together simply by assigning the traditional point scoring system. The AS-level score can be shown to have a different distribution from the A-level score and the relationships between AS-level combinations are different from those among A-level combinations. Furthermore, mixing A- and AS-level results in the basic multivariate model caused convergence problems in our case. Modelling AS-level scores as separate responses enabled us to study the institutional level relationships between A- and AS-level.

The effects of gender, age and type of institution are similar in this study to those of the previous study which used the total A- and AS-level point score (Yang and Woodhouse, 2001). We note, however, that, whereas Yang and Woodhouse found that girls' disadvantages increased with increasing GCSE average score, for mathematics this is not the case, with girls' performances increasing with increasing average GCSE score above a value of about 4. Further research with other A-level subjects would be useful in this respect.

The analysis presented here illustrates the complexity that is involved in making judgments about institutional effects. The importance of adjusting for prior performance, the 'value-added' model, is well understood, but we have shown that the correlation at institution level between subjects and combinations of subjects is often moderate. This 'differential effectiveness' is important information, potentially highlighting institutional strengths and weaknesses that conventional school effectiveness studies often have not tackled. Although our results are limited to A- and AS-level examinations, we would expect our general conclusions to be relevant to examinations taken at other stages in the educational system.

Finally, although this paper has been concerned with mathematics, the methodology extends readily to considerations of other subjects. In principle the approach could be extended to include all subjects taken, although the number of possible combinations is large. One possibility would be to carry out separate analyses for cognate groups of subjects, such as science or languages. Further research along these lines utilizing the data set is planned.

\section{Acknowledgements}

This study is part of the project 'Application of advanced multilevel modelling methods for the analysis of examination data', supported by the UK Economic and Social Research 
Council under grant award R000237394. The Department for Education and Employment kindly provided the examinations data. We are also grateful to Tony Fielding, Trevor Knight, Sally Thomas and John Gray for their helpful advice.

\section{References}

Goldstein, H. (1995) Multilevel Statistical Models, 2nd edn. London: Arnold.

Rasbash, J., Browne, W., Goldstein, H., Yang, M., Plewis, I., Healy, M., Woodhouse, G., Draper, D., Langford, I. and Lewis, T. (2000) A User's Guide to MLwiN, V2.1. London: Institute of Education.

Yang, M. and Woodhouse, G. (2001) Progress from GCSE to A and AS level: institutional and gender differences, and trends over time. Br. Educ. Res. J., 27, 245-267. 